\title{
CULTURAL PROJECTS AND GEOMATIC SURVEYS FOR THE RESILIENCE OF SCHOOL HERITAGE.
}

\author{
C. Palestini ${ }^{1}$, A. Basso ${ }^{2}$ \\ ${ }^{1}$ Department of Architecture, University of the Adriatic Studies “G. D’Annunzio” Pescara, Italy \\ caterinapalestini@libero.it \\ ${ }^{2}$ Free University of Bozen, UNIBZ, Bolzano, Italy \\ alessandro.basso@unibz.it
}

Commission WG II/8, WG III/5, WG V/I

KEY WORDS: Photogrammetry, Resilience, 3d Reconfiguration

\begin{abstract}
:
The contribution, considering the need for an increasingly dynamic and effective knowledge of cultural heritage, able to offer a rapid acquisition, management, monitoring and processing of data, proposes integrated survey experiments conducted with low-cost photogrammetric systems. As part of the research aimed at the recognition of school facilities in Abruzzo, cultural projects aimed at knowledge and conservation have been activated also considering that these buildings are often at risk for critical situations because dated, expanded or readapted without appropriate plans for seismic adjustment even in relation to their delicate tasks. In particular, a project of collaboration between the university and the schools of Pescara was initiated to face a situation characterized by the missing of appropriate technical documentation, the absence of original projects and often the lack of the graphic works in the municipal archives with respect to the current state. The urgency to consider in advance the current state, the performance standards of these degraded public structures that require deep attention achievable with the adjustment of safety standards, difficult to program in the absence of a related survey, has directed the start of the work of analysis from several points of view with multidisciplinary contributions. The three-dimensional detailed models from parametric or manual methodology and their possible inclusion in virtual platforms for archival management of historical data, are functional to the documentation of the actual state, based on the reliable $3 \mathrm{~d}$ survey that constitutes the starting point to retrace the project, its construction phases, transformations, values and problems aimed at addressing conscious restoration interventions and adjustments to safety standards.
\end{abstract}

\section{INTRODUCTION}

The research is born from the need to manage in a planned way the possible dangers induced by the limited maintenance of school buildings, currently increased by the seismic risk, starting in the first place a timely and systematic knowledge of these structures in view of the fragility of the users and the tasks that take place there.

As is well known, Abruzzo has been repeatedly hit by earthquakes that have highlighted the lack of safety of public facilities, specifically education facilities, as evidenced by the serious collapses caused by earthquakes in 2009 and 2016. After the emergency phase that affected the areas near the epicentres, the request for attention and knowledge has extended to a large area of the crater, within the territory included between the coastal strip and foothills.

The municipalities have understood the need to have at their disposal a regional register of school buildings that documents the consistency and the state of conservation, considering the critical issues related to the use of public educational service.

The objectives, determined by the management of risk and resilience for the Cultural Heritage, have defined the cultural project activated through experimental memoranda of understanding drawn up between the Department of Architecture of Pescara University "G. d'Annunzio" and a first nucleus of school buildings in the city, to be implemented over the years to achieve the complete digitization and management of the school heritage (Soler et al., 2017).

The support of geomatics, the integration of information technologies in the three-dimensional acquisition of data, more and more effective and versatile image-based acquisition systems defined as low cost, applied in the field of restoration,

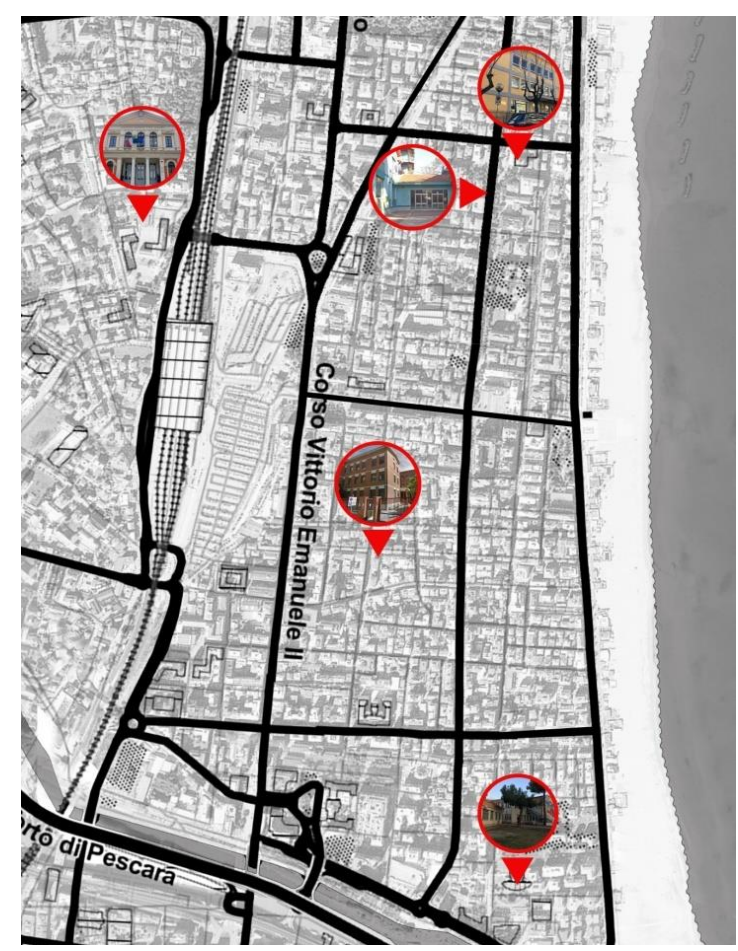

Figure 1. Pescara plan with location of 5 school buildings. 


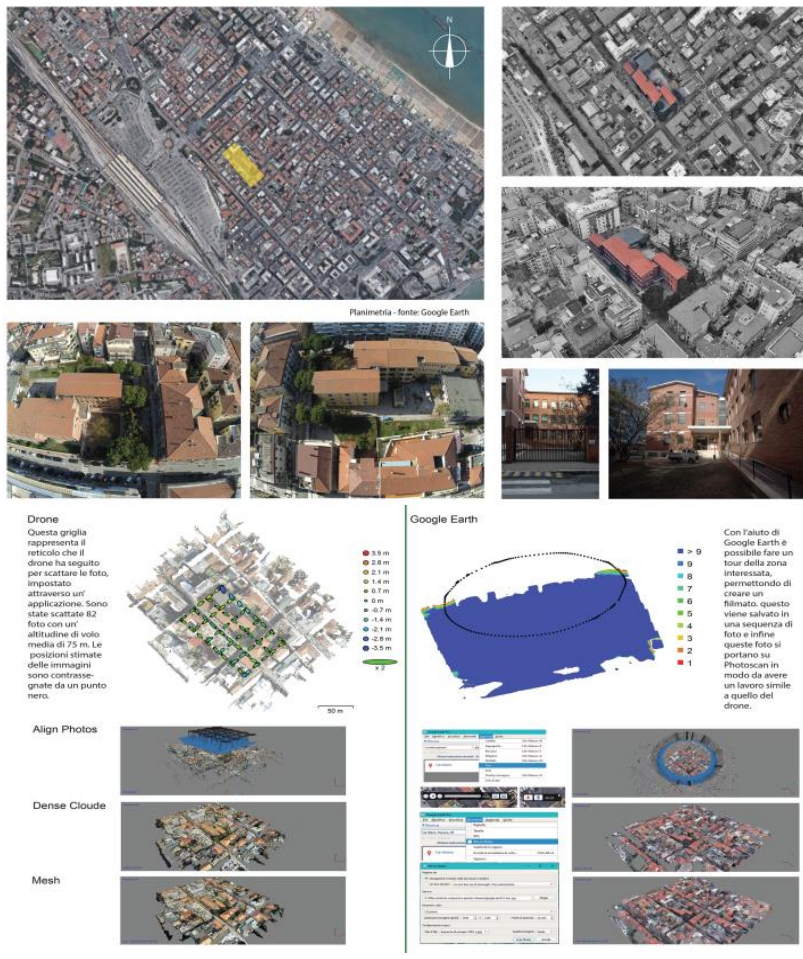

Figure 2. Comparative photogrammetric modelling phases: data acquisition from drone and Google Earth of G. Pascoli school.

protection and management of cultural heritage, provide important synergies to define the conservation process that starts with knowledge, with detection. These premises have motivated the integrated survey operations established in the project that currently involves four Institutes including six schools, including primary, secondary and high schools, in the Adriatic city (fig. 1).

The importance as a preparatory act to the restoration, as an essential prerequisite for the knowledge of the formal, structural and state of affairs of the buildings, has been the leitmotif of the methodology of investigation that is presented in the contribution.

A first acquisition had already involved in 2017 the Tito Acerbo school, historical and representative of the city, built at the end of the nineteenth century, which has highlighted the various transformations that have occurred over the years, represented by the whole detail and implemented with the application of HBIM platform. (Palestini et al., 2018)

The current survey extends the work involving five school structures built after the Second World War, examined through integrated surveys, carried out from the ground and with the help of drones, through three-dimensional study models, derived from objective and dynamic image-based surveys.

The schools examined have similar characteristics and were built between the years 1950-70 with load-bearing structures in reinforced concrete and foundations with backward beams and brick walls plastered or externally covered with bricks. "G. Mazzini" in Regina Margherita avenue, "G. Pascoli" in via Milano, are located in the city center; "Borgomarino" in via G. Puccini is located in the namesake district near the canal port; the institute "IIS Volta" in Alessandro Volta street, structured in the form of a campus is located in a suburban area of the city. These buildings, despite the importance of the public type to which they belong, are not always accompanied by documentation referring to the original project, research missing
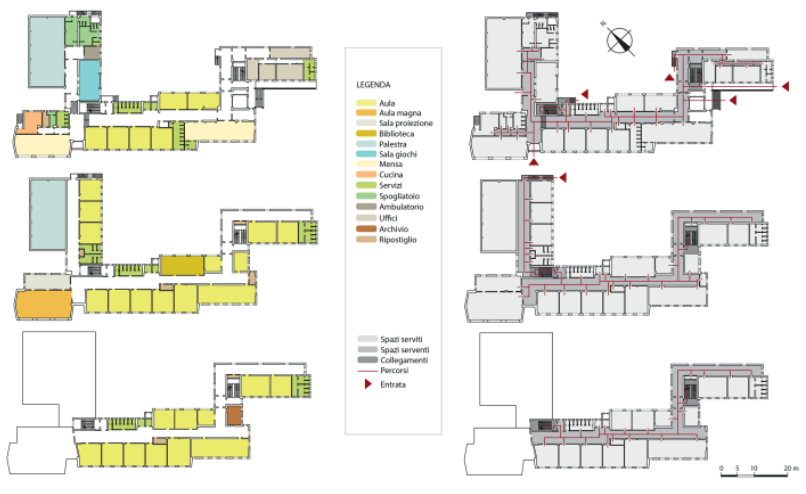

Figure 3. G. Pascoli school: distribution of functions.

or limited to some technical tables, which show the construction systems and designers, generally local engineers.

The plans and graphic documentation acquired by the municipality, in more recent times, are also brief and do not correspond to the actual state. The direct investigation was therefore essential to obtain a graphic reference base suitable for examining the construction characteristics and state of conservation of buildings, especially for the exteriors of inaccessible points and roofs, for the interiors of common areas, nodal points such as vertical connections and analysis of the environments and their functions with respect to escape routes and the requirements established by safety standards.

The working methodology developed to build an operating system capable of providing a rapid digitization of the school heritage, has been organized into phases and levels of study differentiated, formulated according to the general characteristics and individual peculiarities.

For all the structures, drone-shaped shots have been planned, reattached with image-based surveys carried out from the ground, obtaining, as documented in the following chapters, threedimensional models from which the informative and thematic contents have been extrapolated according to the different study needs.

\section{INTEGRATED COMPARISON METHODOLOGIES AND ANALYTICAL GRAPHIC RESULTS OF SYNTHESIS OBSERVATION MODALITIES.}

A plan of collaboration between universities and schools in Pescara started an analysis project on some of the many schools in the city, in fact compensating for some serious problems belonging to these public structures, such as the lack of appropriate technical documentation, the absence of the original projects and often the mismatch of the graphic works in the municipal archives with their current state, elements that may call into question any projects of intervention on the conditions of aesthetic and structural degradation in which these buildings still face. In this regard, multidisciplinary contributions have made use of low-cost methodologies of investigation and survey, proposing new tools and new approaches to knowledge of the school heritage, using image-based systems, used from the ground and from drones, specifically organized to obtain three-dimensional models from which to extract information and thematic content according to the different needs of study. The urgency of having to compare, in a relatively short time, several school buildings of considerable size, and at the same time to verify the few archive documents available, has necessarily directed us towards techniques of three-dimensional photogrammetric survey, or photo modelling, system that has 
been able to return correct three-dimensional models of the actual state used skilfully as models of digital comparison between the wall envelopes and the few design drawings available, considering these obsolete structures the compositional differences and screening the dissimilar aspects of their protection, which on the one hand aims to maintain the characteristics of their identity and on the other is projected to implement correct adjustments and maintenance operations. The reduction in the time required for graphic returns, due to the complexity of the executive workflow that accompanied the traditional stages from metric data acquisition to scale representation, now allows for more precise and faster processing (Barazzetti et al., 2015). While in the past data deriving from the manual survey were synthesized from the drawing, with the consequent loss of a lot of information, taking the photographic documents not in scale exclusively as
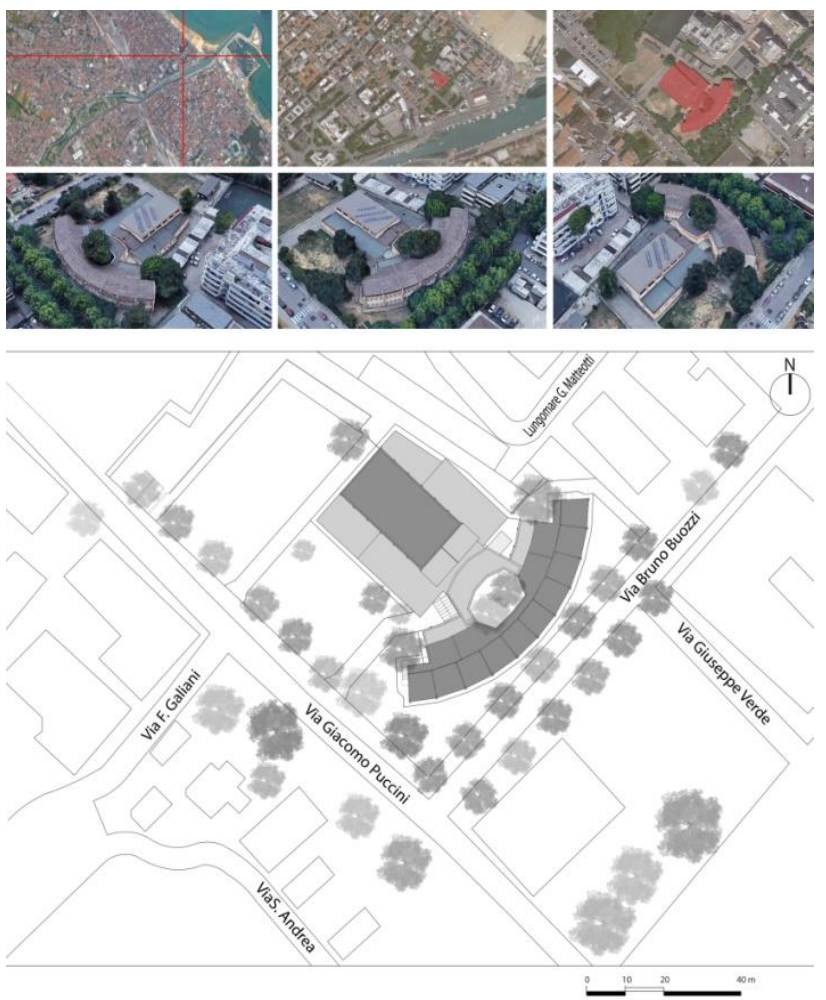

Figure 4. Localization and acquisition of drone photo-data from the Borgomarino school.

a proportional reference and graphic info of the materials used, today the integrated photogrammetric $3 \mathrm{~d}$ survey offers excellent results and a much more complete reconstruction of the information (Cundari, 1984). In the case studies, the use of terrestrial and aerial photogrammetry, supported by UAV, Unmanned-Aerial-Vehicle systems (fig. 4), plus an experimental photogrammetric survey, carried out by virtual drone on Google Earth's open source data, allows a threedimensional graphic return through the autogeneration of triangular meshes, typical of Image Based systems, and the implementation of manual modelling techniques, nurbspoligonal-sculpting, based on two-dimensional photoplans, or developed on reference, from pre-generated $3 \mathrm{~d}$ assets (Palestini et al., 2019). The results obtained from the various acquisitions were compared and examined to check the level of accuracy and useful information for the achievement of the required purposes. For the survey of the buildings were used some well-known software, such as Agisoft Photoscan and Pix4d, working with shots from the ground resulting from the use of simple digital cameras and partly using a small drones Parrot Anafi with installed a camera Gopro with integrated Gimbal stabilizer, from which were then taken full hd frames that have reconfigured in great detail the structure of the high parts. The use of systems that work with photography, using passive sensors and precisely exploiting the diffused lighting present in the environment, allows a considerable level of detail, both geometric plastic level, respecting modules and proportions of the product, both aesthetic and chromatic level in relation to the material information of the coating. It is necessary to use as a guide to the three-dimensional redesign the data acquired in the form of point clouds or triangulated meshes on specific modelling platforms, with parametric or manual management, in function of their possible insertion in archival management software of historical data. Image Based detection systems are based on Structure from Motion, an automated 3d digital reconstruction generated by frames taken in motion sequences,
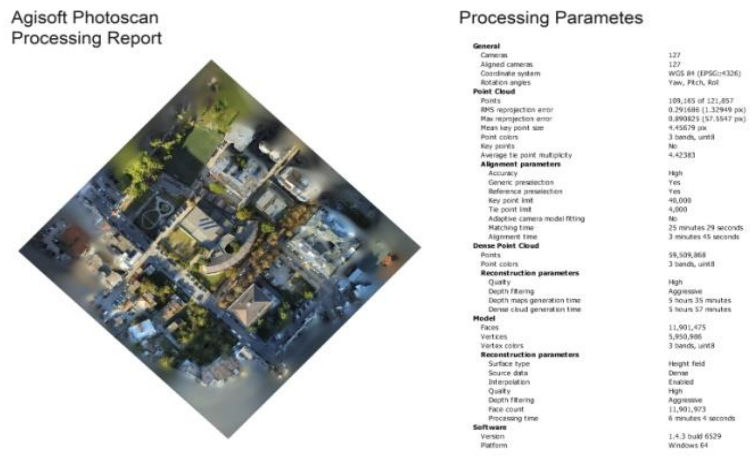

Survey Data

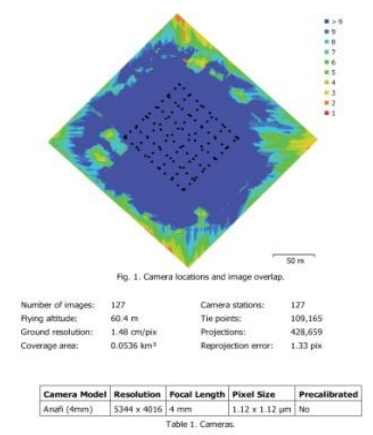

Camera Locations

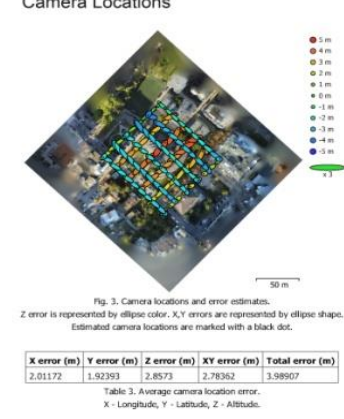

Figure 5. Agisoft Photoscan processing report of Borgomarino school. Survey data and camera location.

structuring a procedure that is divided into four main phases. The first, following the input of the photo-data into the computer, consists of the alignment of the different shots of the camera with a photocentric or progressive shooting technique: in this phase the software analyzes all the photos, searching for the homologous points in relation to the chromatic peculiarity and the light exposure factor; for each image the orientation of the camera and the relative calibration parameters are identified, from which the coefficient of distortion of the lens is also obtained. From this elaboration is generated, through an automatic collimation, a "Point Cloud Based", that is a widespread point cloud made up of the "Key points" necessary to hook in a Cartesian coordinate system the spatial model of the detected object: in this phase we can start to outline the contour of the object in a three-dimensional environment with the indications relative to each single camera shot of the capture. In this phase we already understand the problems related to the entered images, the error percentages and any distortions to be corrected. In the second phase of the workflow 
a thicker "Dense Point Cloud" is configured, obtained on the basis of the positioning of the estimated shooting points, from which the program extracts information about the color and plastic detail of the object (Smith, 2000).

The Dense Point Cloud, which requires more hours of calculation both using the CPU and the GPU, can be modified, cut and optimized according to the next phase, that is, the construction of the meshes through the SfM algorithm, which "covers" the points with a network of triangles to generate a mesh surface called T.I.N, or "Triangulated Irregular Network", considering each point of the cloud as a vertex of a contiguous and irregular triangular polygon with a $\mathrm{Z}$ coordinate, effectively transforming the point cloud into a polygonal model. It is useful to point out that, unlike the Laser Scanner, from which you get an "ordered" point cloud with a scanning step consisting of rows and columns, Image Based systems create a very dense but "messy" network of points, producing polygonal meshes with irregular topology, configured according to a logic of calculation produced by the data and photographic information entered (fig. 6). It may therefore be necessary to intervene on the topology of these self-generated 3D models and on their polygonal density according to the desired graphic-visual quality, but also in relation to the scale of the required survey. In this phase it is very often possible to encounter problems or definition errors due to the so-called digital disturbance, or "noise", such as the vegetation that often in photographic shots tends to cover part of the structures, generating in fact gaps and imperfections that make the 3D model unsuitable for the next phase. It is necessary to make some corrections, reducing the polygonal density of the meshes, removing unnecessary disturbance components, accidentally calculated because present in the frames, or closing the gaps in the 3D models of the detected artifacts, often critical individuation of excessively concave parts, convex or the result of a misunderstanding by the software of inaccessible points and too high. For a possible retopology of the meshes and correction and improvement of the texture channels, we have also opted for the inclusion in the workflow of Pixologic Z-brush, a program that is used in the film and art sector able to exploit the power of Voxel algorithms to easily manage hundreds of thousands of pixels. Among the various features of the Pixologic software are very useful those related to automatic retopology, digital painting, detail projection and corrective sculpting through polygonal subdivision, fundamental operations for an optimal management of three-dimensional models generated through photo modelling. The creation of the meshes is followed by the fourth and final phase, functional to the acquisition of the texture applied to the geometric model, carried out through an orthographic projection by UV Map of the colour data taken from the pixels of the photos previously used for the operations of geometric three-dimensional photogrammetry. A Diffuse map and a Normal Map are then generated, necessary for the detailed and photorealistic rendering of the $3 \mathrm{~d}$ model obtained, which can be exported and possibly implemented on external digitized archive platforms that support RTR (real time rendering) (fig. 14).

\section{CASE STUDIES. THE SURVEY OF SCHOOL BUILDINGS BY MULTISCAL PHOTOMODELING TECHNIQUES.}

Specifically for the research in question, in which the same executive pipeline was used for the survey of all the school buildings under examination, the phase of alignment of the shots immediately gave discreet results, returning a scattered point cloud already equipped with RGB data from the photographs themselves. The aerial images from the RPAS
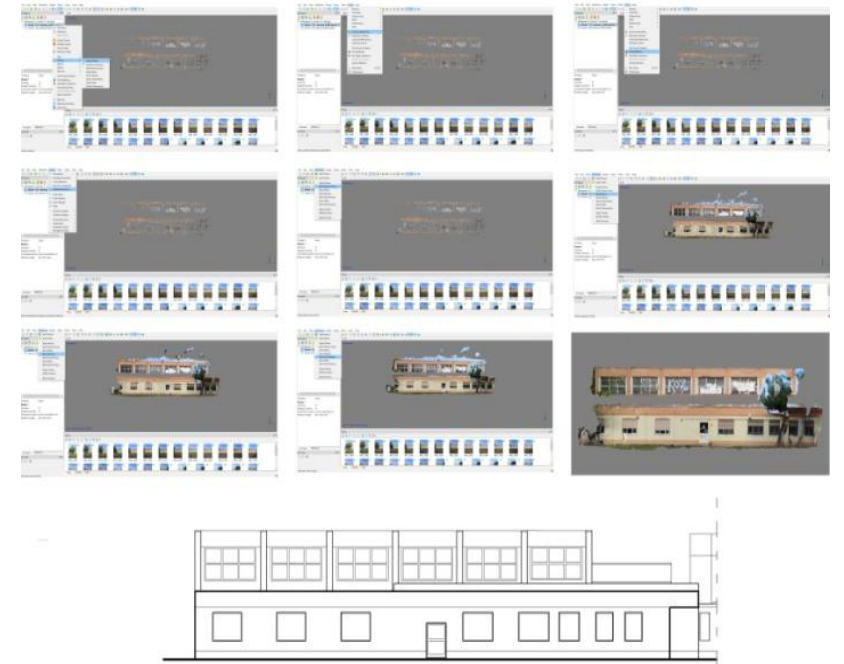

Figure 6. Digital reconstruction phases of a Borgomarino school facade, photoplane edit and CAD retitution.

drone system and those from Google Earth Pro (figg. 2-5), on the other hand, provided a solid support point that relates the institutes under examination with the surrounding urban territory. Specifically, a consumer drone with easy portability was used, equipped internally with a GPS system fundamental for a geolocation of the resulting three-dimensional model.

The flight plan was structured using apps for smartphones, and the flight phase and aerial image acquisition was almost completely automatic, providing data with an admissible error in centimeters considered on the flight altitude and resolution of the optics. At an experimental level, the aerial drone images have been integrated by screen-shots acquired from the Google Earth Pro platform, allowing through the same photogrammetric techniques the extrapolation of plastic three-dimensional spatial data and information on color impossible to export directly to other platforms (as owned by Google).

The procedure consists in the virtual simulation of drone flight, proposed with the aim of extracting the image data necessary for the subsequent phases of photomodelling, and is based on a virtual tour that follows a predetermined path with an angle of about $45^{\circ}$ within the macro areas in overlap (fig. 12).

Assuming to drive a virtual drone according to a checkerboard path, imagining the path of Google planes, through a precise subdivision into submodules, precise nodal points are identified around which to take shots with the technique of central photography, thus acquiring three-dimensional data in the round both relating to the geomorphological conformation of the ground, both regarding the layout and height of the built. The numerous frames obtained from the video of the virtual tour have been processed in Agisoft Photoscan, just as it was done for the acquisitions from the ground and from RPAS drone, in order to obtain through the same procedure of alignment of the homologous pixels, a dense cloud points, from which was generated, exploiting the same points as vertices, the triangular polygonal mesh of a much larger area, on average detailed enough to trace plastic connotations similar to the reference model (Palestini et al., 2019). The photomodelling workflow thus provides three effective multi-scale visual insights, that of the buildings themselves, that of the proportional relationship between the school building and the surrounding buildings, and that on an urban scale in which all the schools examined converge, comparing different analytical graphic results and at the same time unifying the entire work in an integrated mode of synthesis observation (fig. 13). 
In order to manage the highly detailed point cloud in a more fluid way, streamlining the hardware calculation of the data, we opted, especially for the terrestrial survey, for a preventive decomposition in "chunks" set according to the different sectors of the construction (De Luca, 2011).

In order to allow the correct merge of the individual clouds, before calculating the mesh, precautionary operation is performed to identify precise visible marker points, positioned in specific areas of the main facades, through which it is possible to reconnect the photogrammetric survey sessions.

The operation of joining by chunk, prior to the calculation of the mesh, is more precise because the software, working on photogrammetric data contained directly in the point cloud, correctly determines each marker identified by the corresponding points of a pair of photos, an operation that in the next phase, when the program has already developed a continuous three-dimensional surface, can generate errors in polygonal interpolation at the models, due to a different topology automatically generated during the phase of "meshing" the point clouds acquired in different sessions.

For the survey of each single school building, it was sufficient to operate through 4 sessions-chunks, each relating to a facade of the buildings, which subsequently, during the meshing phase, were then combined into a single $3 \mathrm{~d}$ editable model.

The main prerogative of this method of detection lies not only in the economic savings of individual operations, but especially in the possibility of a non-invasive survey, considering these are fragile buildings and still in use by vulnerable groups such as children, resulting from the achievement of basic data for the phases of modelling and transfer to virtual platforms questionable archival asset. Similarly, for the internal spaces, for the survey of the most complex and articulated environments such as the central staircases, the magne classrooms and in some cases the wide corridors, the direct metric data acquisition has been integrated with the photogrammetric image based terrestrial system, from which schemes for the classification of the architectural functions of the common spaces are obtained (fig. 3).
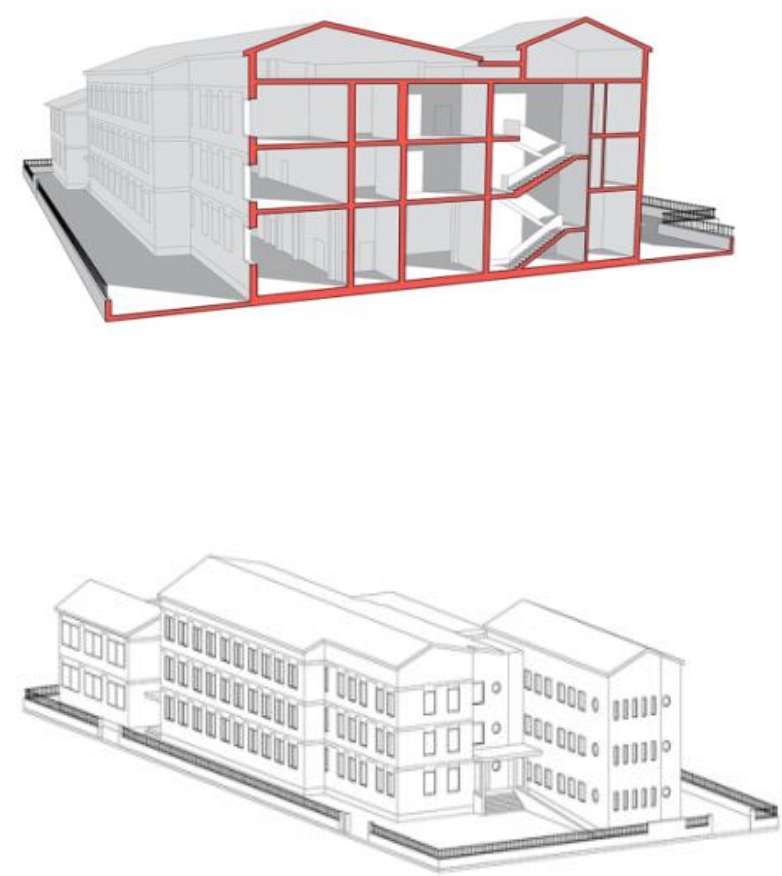

Figure 7. Section and axonometric synthesis of the G. Pascoli school.
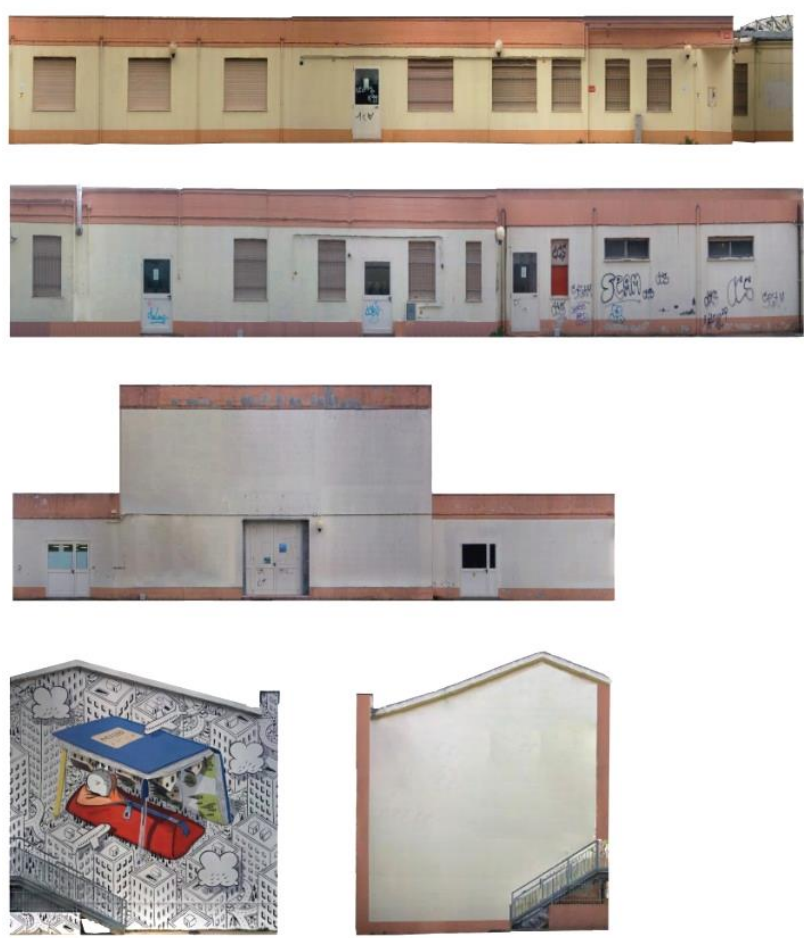

Figure 8. photoplane of the school Borgomarino facades. Murales by the Millo artist as part of a redevelopment project.

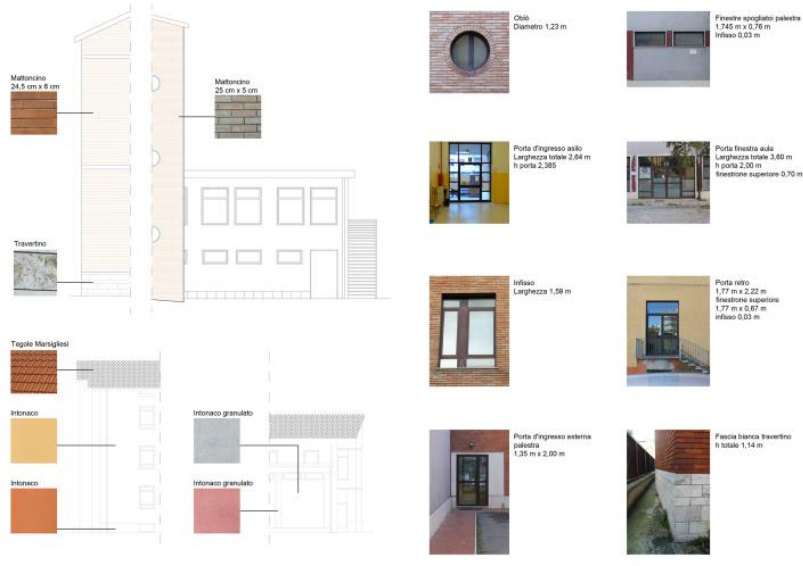

Figure 9. Photographic materials abacus of the G. Pascoli school in Milano street.

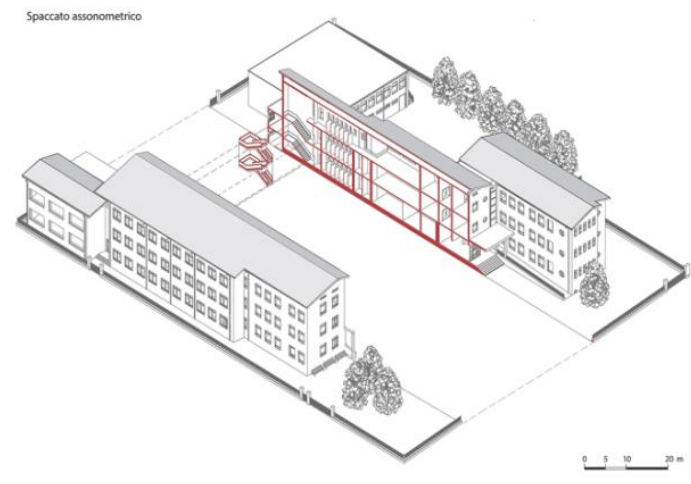

Figure 10. Axonometric exploded view of the building. 

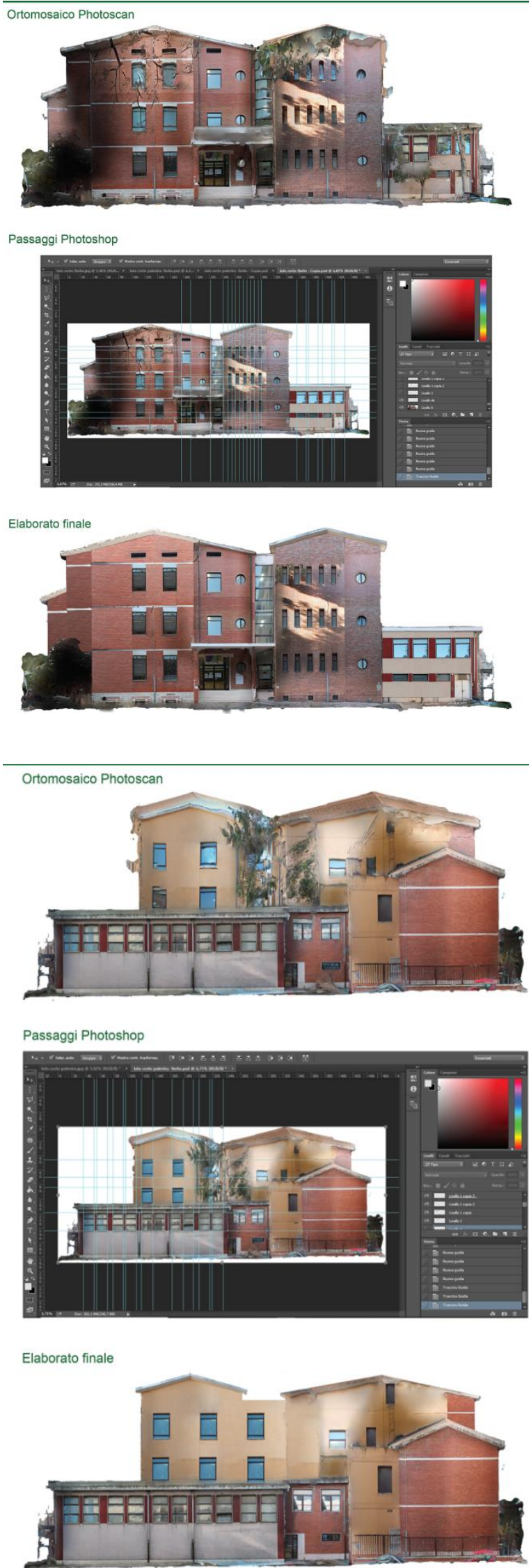

Figure 11. Phases of cleaning and graphic integration of photoplane from photomodelling.

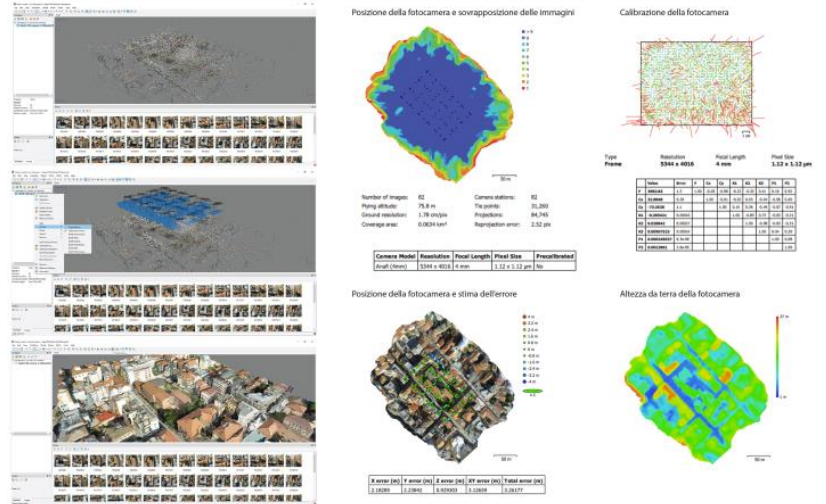

Figure 12. The measurement acquired by Earth photomodelling.

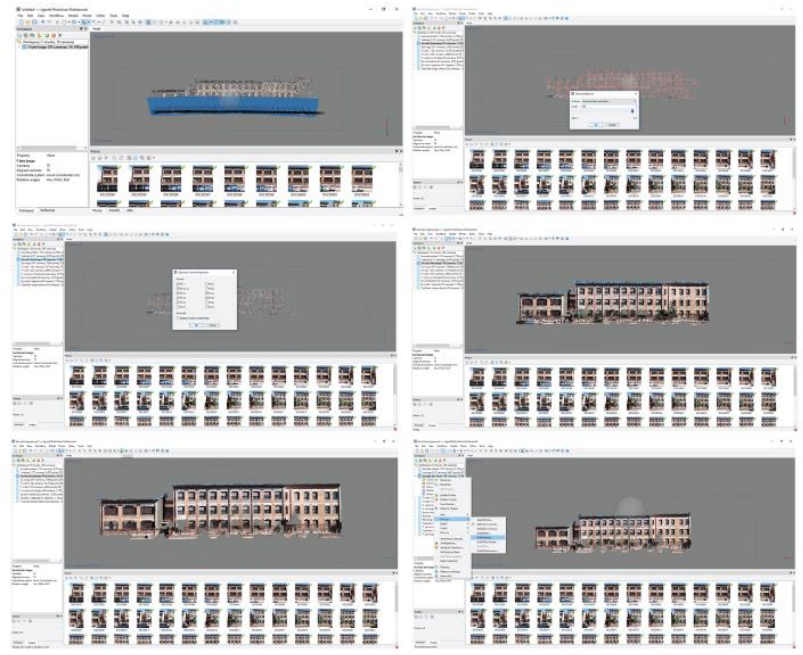

Figure 13. Terrestrial photomodelling on the side facade of the G. Pascoli school.

\section{CONCLUSIONS}

The work does not involve a closed conclusion, but an open operating system that can be integrated and interconnected with parametric data management software (Bruno et al., 2018).

In particular, as can be seen from the images reported for one of the schools examined, that of Borgomarino (fig. 15), the data resulting from the survey were exported to simulate a management with the Revit software, which supports the procedural processes and formats of Bim import-export, supporting the multidisciplinary collaborative process (Napolitano et al., 2018). In the proposed steps, it can be seen how from the import of $3 \mathrm{D}$ assets it is possible to determine parameters for each family to be taken into account, for example in the case of schools those to be considered, such as internal and security stairs, roofs, structures, load-bearing and perimeter walls, classrooms, internal and exit doors, windows. In this way, we obtain tables that collect the categories examined that can be questioned for the ordinary management and planning of conservation procedures. The system makes it possible to coordinate the actions to be programmed according to the critical situations detected (Palestini et al., 2018).

The analysis conducted through three-dimensional study models has also allowed exploration with specific representations: sections and views exploded in 3D, volumes and their decomposition (fig. 17). The views allow to visualize the outside and the inside of the architectural box in the nodal points as the stairs (figg. 7-10). In addition to the structural and 
quantitative aspects, it is important to focus on the preservation of the identifying characteristics of the school heritage, which often transforms spaces in the process of adaptation, neglecting the compositional aspects, linked to a fragile architecture and not subject to constraints such as that built after the Second World War (Palestini, 2017). In this sense, the research documents in particular the layout of the rooms, the internal finishes and the organisation of the open spaces for the sports facilities and the relevant green areas. The developed survey method focuses on the knowledge of the different schools, while on the one hand proposing univocal criteria, useful to unify the general management procedures, on the other hand extrapolates the characteristics of each building.

Specific thematic tables analyse materials and finishes: for example, the school in Milano street is characterized in the main facades by a coating of bricks interrupted by string-course bands that highlight the three levels of elevation (fig. 11). In the other structures, plaster with pastel colours prevails, reinforced in some parts in contrast to underline the various floors and windowed surfaces (figg. 9-16). The latter in most cases are in anodized aluminium, revealing the replacements made in the 1980s and 90s. No attention has been paid to energy efficiency based on traditional heating systems.

Finally, there is an interesting social initiative carried out by a group of mothers, formed in an association for Abruzzo resilient for the neglected school of Borgomarino, located in a popular area. The association has supported the creation of a mural produced by a well-known street artist, to improve the aesthetic aspect by placing the emphasis on security in schools (fig. 8). Aimed at focusing attention on the need for safety in the school, this contribution aims to support specific plans of intervention with the analyses carried out, defining projects of rehabilitation, conservation and consolidation. The aim is to provide an operational platform, a useful tool that we hope the administration will adopt to plan in a conscious manner future measures, a pilot project in which the input of geomatics and conservation merge in the governance of the management of the school heritage (Inzerillo et al., 2016).

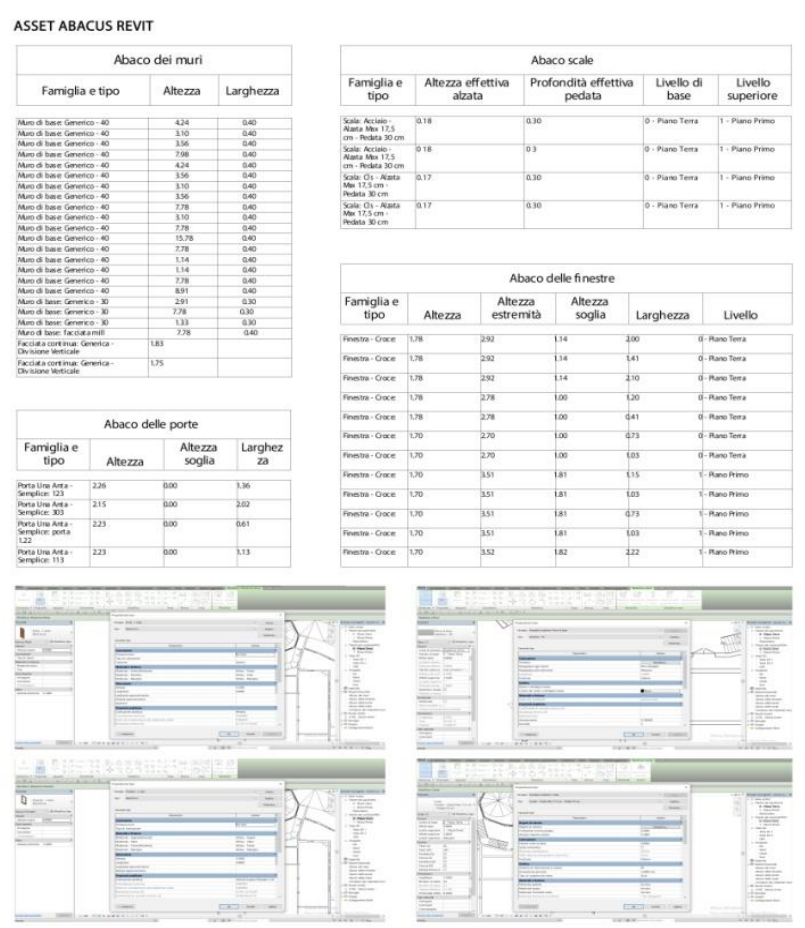

Figure 15. (A) Revit script data abacus of elements.
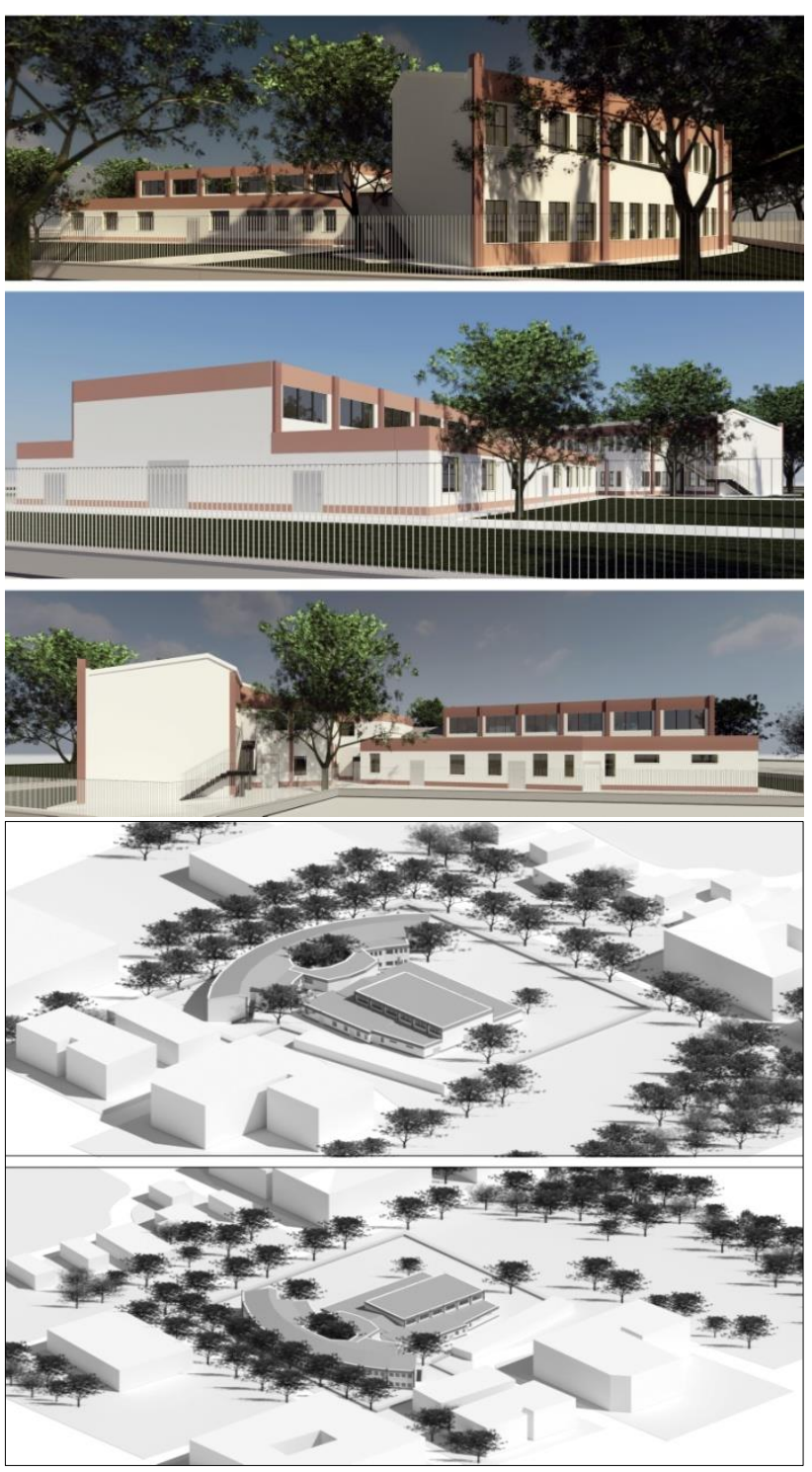

Figure 14. Revit renders of Borgomarino school.
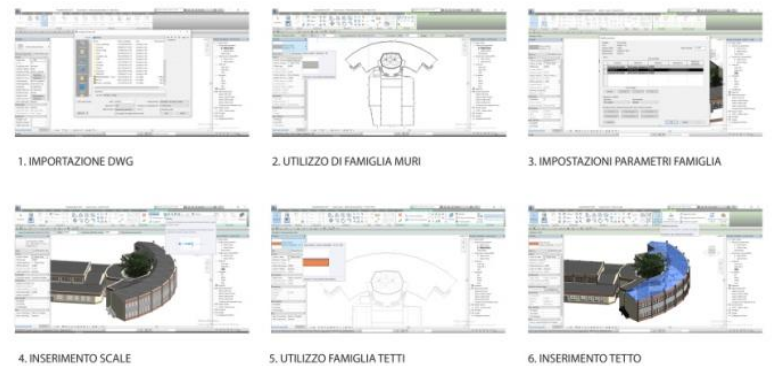

4.INSERMENTO SCALE

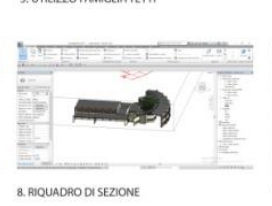

INSERMENTO TERTO
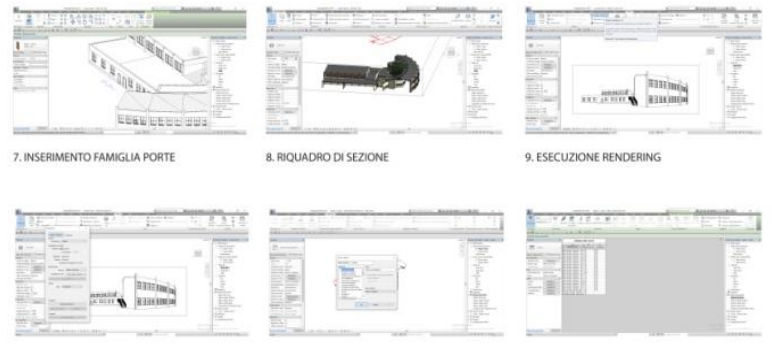

Figure 15. (B) Revit_graphic abacus of architectural assets. 

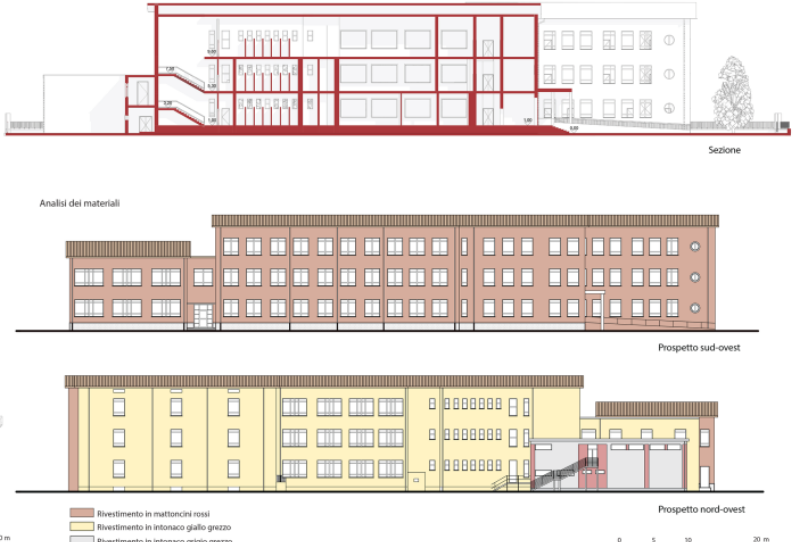

Figure 16. side facades of the G.Pascoli school, graphic representation of the materials in their current state.

\section{ACKNOWLEDGEMENTS}

The authors would like to thank in particular the people involved in the acquisition of data and in the campaign on site including Franz Lami for the filming and processing by drone. We also thank the students of the Architectural Survey course of the G. d'Annunzio university for the graphic drawings provided.

\section{REFERENCES}

Barazzetti, L., Banfi, F., Brumana, R., Oreni, D., Previtali, M., Roncoroni, F., 2015. HBIM and augmented information: towards a wider user community of image and range-based reconstructions, In: The International Archives of the Photogrammetry, Remote Sensing and Spatial Information Sciences - ISPRS Archives, Vol. XL-5/W7, 35-42.

Bruno, S., De Fino, M., Fatiguso, F., 2018. Historic Building Information Modelling: performance assessment for diagnosisaided information modelling and management, Automation in Construction, 86, 256-276.

Inzerillo, L., Lo Turco, M., Parrinello, S., Santagati, C., Valenti, G.M., 2016. BIM and architectural heritage: towards an operational methodology for the knowledge and the management of Cultural Heritage, DISEGNARECON, 9/n16, 19.

Napolitano, R.K., Scherer, G. and Glisic, B., 2018. Virtual tours and informational modeling for conservation of cultural heritage sites, Journal of Cultural Heritage, 29, 123-129.

Palestini, C., 2017. L'analisi del disegno per la tutela del patrimonio architettonico scolastico. pp.219-226. In ReUSO Granada 2017 Sobre una Arquitectura hecha de tiempo ISBN:9788433861313 vol. 1 Metodologìa, Técnica $y$ Conservaciòn.

Palestini, C., Basso, A., 2019. 3d detection and reconstruction experiments in river basins., In: International Archives of the Photogrammetry, Remote Sensing and Spatial Information Sciences - ISPRS Archives, XLII-2/W9, 2019, 543-550.

Palestini, C., Basso, A. and Graziani, L., 2018. Integrated photogrammetric survey and bim modelling for the protection of school heritage, applications on a case study, In:
International Archives of the Photogrammetry, Remote Sensing and Spatial Information Sciences - ISPRS Archives, Volume XLII-2, 2018, 821-828.

Palestini, C., Basso, A., 2017. Geomatics as a survey tool to document and enhance the cultural and landscaped heritage of the monumental complexes in the mountains of Abruzzo, In: International Archives of the Photogrammetry, Remote Sensing and Spatial Information Sciences - ISPRS Archives, XLII-5/W1, 373-380.

Smith, J., 2000. Remote sensing to predict volcano outbursts. In: International Archives of the Photogrammetry, Remote Sensing and Spatial Information Sciences, Kyoto, Japan: Vol. XXVII, Part B1, pp. 456-469.

De Luca, L., 2011. La Fotomodellazione Architettonica. Palermo, Italia: Flaccovio D. Editore.

Cundari, C., 1984. Fotogrammetria Architettonica. Bologna, Italia: Kappa Ed.

Soler, F., Melero, F.J., Luzón, M.V., 2017. A complete 3D information system for Cultural Heritage documentation, Journal of Cultural Heritage, 23, 49-57.
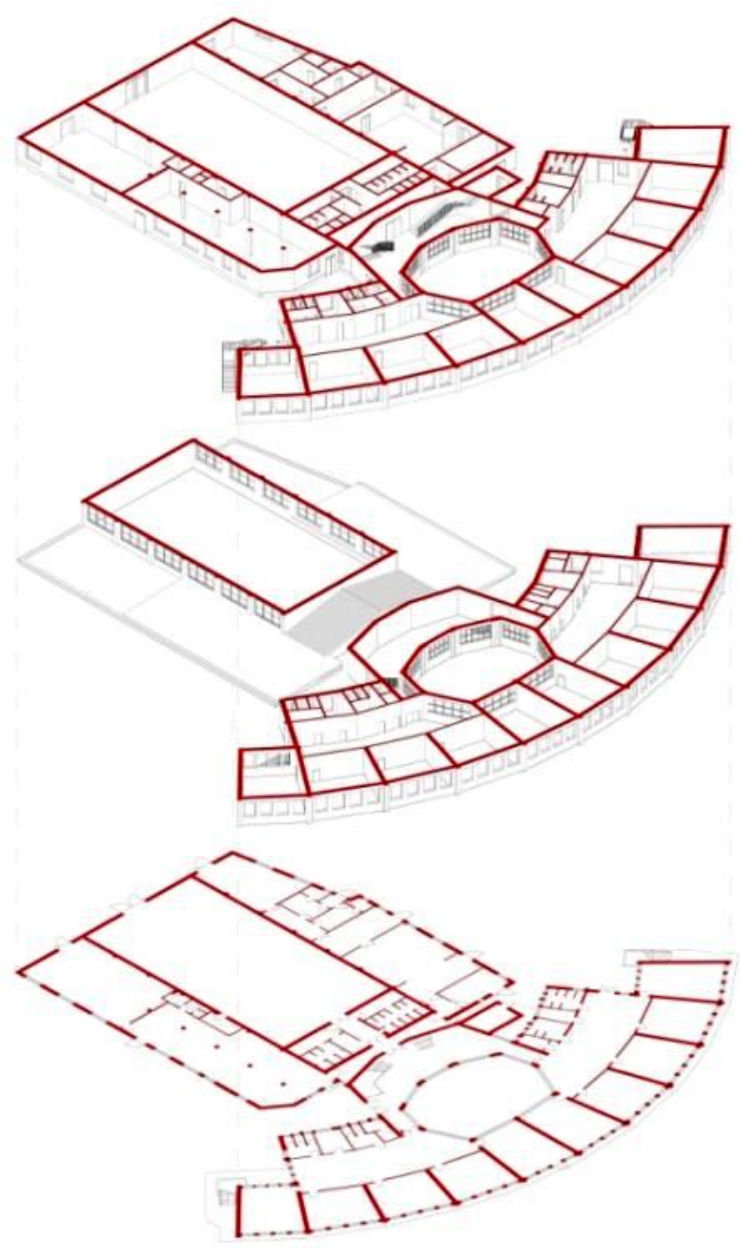

Figure 17. Axonometric sections of the Borgomarino school. 